\title{
March 2020 Pulmonary Case of the Month: Where You Look Is Important
}

Richard A. Robbins, MD

Anselmo Garcia, MD

\author{
Arizona Chest and Sleep Medicine \\ Phoenix, AZ USA
}

\section{History of Present IIIness}

A 47-year-old woman was seen for the first time in our clinic. She had approximately a two-year history of gradually increasing shortness of breath to the point where she could only climb one flight of stairs. In addition, she has a history of a cough sometimes productive and sometimes nonproductive. She did hear herself wheeze intermittently.

\section{$\mathrm{PMH}, \mathrm{SH}$, and $\mathrm{FH}$}

She has a past medical history of gastroesophageal reflux disease (GERD). She was a nonsmoker and had no occupational exposure. Her aunt has a history of asthma.

\section{Physical Examination}

Her physical examination was normal and her lungs were clear.

Which of the following is appropriate at this time?

1. Reassurance

2. Treat empirically for post-nasal drip

3. Treat empirically with albuterol

4. Treat empirically with omeprazole

5. None of the above 


\section{Correct \\ 5. None of the above}

In general, it is a bad idea to treat patients empirically. The three most common causes of chronic cough in a nonsmoker are asthma, GERD, and post-nasal drip (1). However, this patient has shortness of breath as a predominant complaint. While asthma usually responds well to therapy, GERD is particularly problematic, often not responding to aggressive therapy (2). Asthma would be the most likely diagnosis in a patient this age with complaints of dyspnea and cough

Which of the following are appropriate at this time?

1. Chest x-ray

2. Prescribe albuterol

3. Spirometry

4. 1 and 3

5. All of the above 


\section{Correct!}

\section{1 and 3}

If you chose to use albuterol, you need to go back and read the section on empirical therapy. She had seen a variety of physicians for this including another pulmonologist and had been prescribed bronchodilators and even a course of prednisone which did not help. Despite this, she was told that she had COPD. In our general pulmonary practice, we consider chest radiography and spirometry to be almost an extension of the physical examination and likely to produce the most rewarding results. Certainly, spirometry is important in evaluating dyspnea and the chest $x$-ray is considered important in evaluating asthma, the patient's most likely diagnosis $(3,4)$. Her chest $x$-ray (Figure 1) and spirometry are shown below.

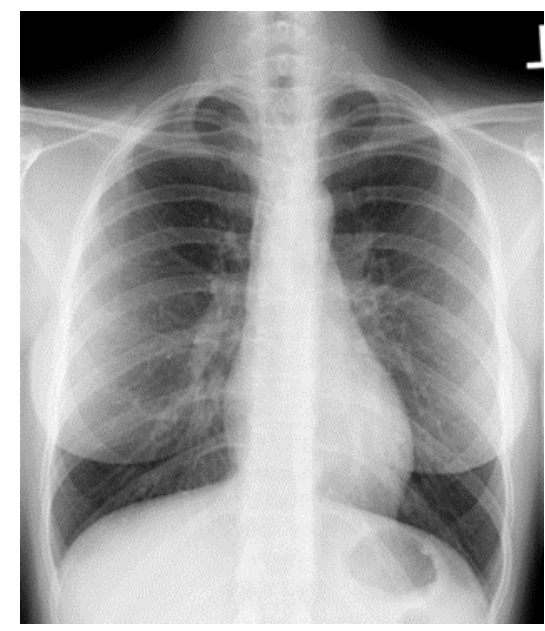

Figure 1. Initial chest x-ray.

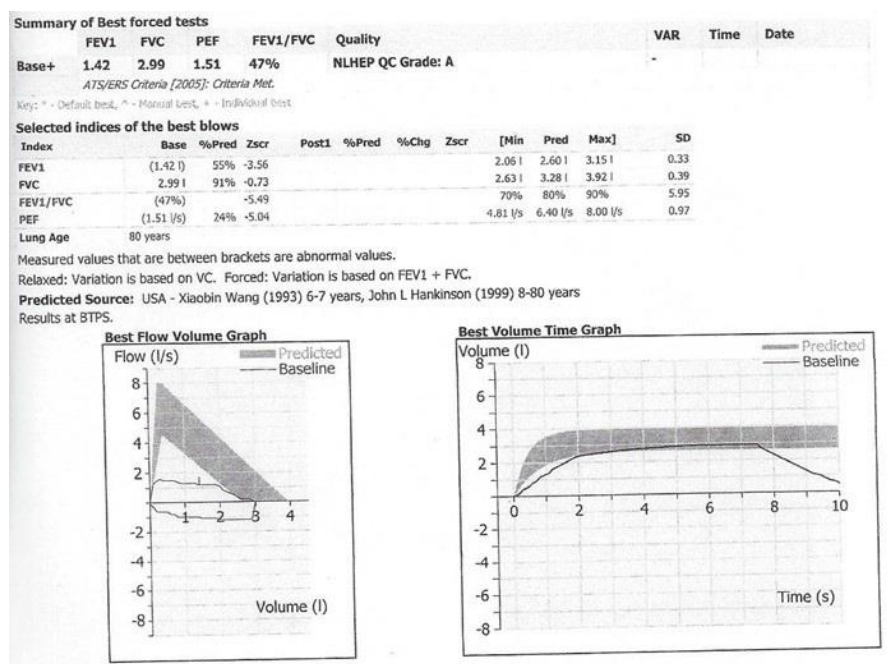

Automatic Interpretation: (ATS) Autonits interpretation cannot exempt from a personal interpretation.

Base: Moderate Severe Obstruction

Figure 2. Spirometry. Post-bronchodilator spirometry was unchanged. 
Which of the following is correct?

1. The chest x-ray shows enlarged pulmonary arteries.

2. The chest $x$-ray shows multiple arteriovenous malformations.

3. The spirometry shows fixed airway obstruction.

4. The spirometry shows mixed obstruction and restriction.

5. The spirometry shows moderate severe airway obstruction consistent with asthma. 


\section{Correct!}

\section{The spirometry shows fixed upper airway obstruction.}

The chest $x$-ray is normal. The pulmonary arteries are normal sized and there are no masses which could be arteriovenous malformations. The spirometry was interpreted by the computer as showing "moderate severe obstruction", which although true, is only part of the story. The FEV1 is decreased but the shape of the flow-volume loop is squared indicting fixed obstruction. The squaring is caused by decreased flows during both inspiration and expiration.

Which of the following is the most likely diagnosis?
1. Asthma
2. Endobronchial tumor
3. Goiter causing tracheal compression
4. Subglottic stenosis
5. Vocal cord dysfunction 


\section{Correct! \\ 5. Vocal cord dysfunction}

Asthma would be expected to show airway obstruction which is reversible by a bronchodilator. An endobronchial tumor is possible but very uncommon. A goiter causing tracheal compression is also possible but usually the goiter is quite large and the patient had a normal neck exam. Subglottic stenosis is also possible but usually associated with a history of prolonged intubation which she did not have. Vocal cord dysfunction (VCD) is often seen in women between the ages of 20-40 years but is increasingly being recognized in men and other age groups (5). Spirometry often shows fixed upper airway obstruction in VCD (6).

What should be done to diagnose VCD in our patient?
1. Bronchoscopy
2. CT scan of the neck
3. Flexible fiberoptic laryngoscopy
4. 1 or 3
5. Any of the above 


\section{Correct!}

\section{1 and 3}

CT scan is not unreasonable if looking for a goiter but is unlikely to show VCD. Both ENT and pulmonologists can evaluate the upper airway. A series of maneuvers is often done to elicit VCD if it is not readily apparent (5). However, the vocal cords appeared normal and there appeared to be a web obstructing the trachea (Figure 3).

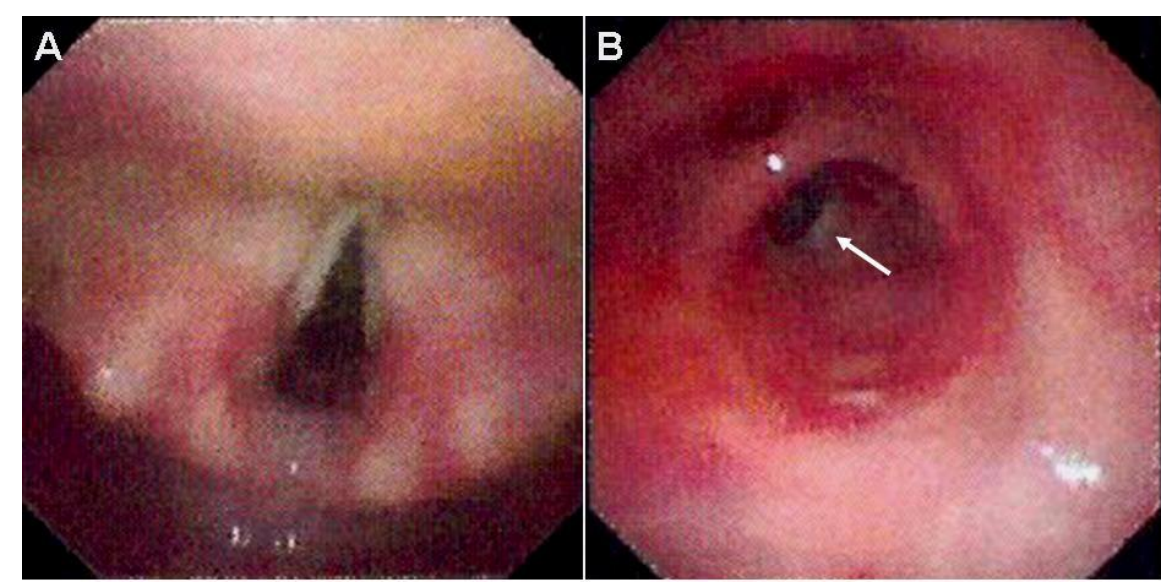

Figure 3. Photos taken through the bronchoscope. A: normal appearing vocal cords which adducted normally. B: view from just below the vocal cords of a tracheal web (arrow) obstructing much of the trachea.

The adult fiberoptic bronchoscope (outer diameter $6 \mathrm{~mm}$ ) could not be passed beyond the web.

What should be done next?

1. Extended partial cricotracheal resection

2. Laryngotracheal reconstruction

3. Laser bronchoscopy

4. Thoracic CT scan

5. VATS 


\section{Correct! \\ 4. Thoracic CT scan}

Tracheal webs in adults are rare and usually due to endotracheal intubation. In children they are also rare and usually congenital. We believe this was a congenital tracheal web in an adult (7). Since her aunt also had a similar problem, the web may be congenital. CT is performed to assess the vascularity, extent and position of the web (7). We referred the patient to an invasive pulmonologist and understand she is doing well after laser bronchoscopy.

\section{References}

1. Palombini BC, Villanova CA, Araújo E, Gastal OL, Alt DC, Stolz DP, Palombini CO. A pathogenic triad in chronic cough: asthma, postnasal drip syndrome, and gastroesophageal reflux disease. Chest. 1999 Aug;116(2):279-84. [CrossRef] [PubMed]

2. Kahrilas PJ, Altman KW, Chang AB, et al. Chronic cough due to gastroesophageal reflux in adults: Chest guideline and expert panel report. Chest. 2016 Dec;150(6):1341-60. [CrossRef] [PubMed]

3. Oelsner EC, Lima JA, Kawut SM, Burkart KM, Enright PL, Ahmed FS, Barr RG. Noninvasive tests for the diagnostic evaluation of dyspnea among outpatients: the multi-ethnic study of atherosclerosis lung study. Am J Med. 2015 Feb; 128(2): 17180. [CrossRef] [PubMed]

4. Rubenstein HS, Rosner BA, LeMay M, Neidorf $R$. The value of the chest $X$-ray in making the diagnosis of bronchial asthma. Adolescence. 1993 Fall;28(111):505-16. [PubMed]

5. Kenn K, Balkissoon R. Vocal cord dysfunction: what do we know? Eur Respir J. 2011 Jan;37(1):194-200. [CrossRef] [PubMed]

6. Sanz Santiago V, López Neyra A, Almería Gil E, Villa Asensi JR. Spirometry patterns in vocal cord dysfunction. An Pediatr (Barc). 2013 Mar;78(3):173-7. [CrossRef] [PubMed]

7. Jafar N, Islam E, Alalawi R. Shortness of breath caused by a tracheal web. SWRCCC 2015;3(9):52-4. [CrossRef] 